\title{
Lyrics about Physics
}

n Tatiana Balachovsky - Curator of the Kapitsa Museum - DOI: 10.1051/epn/2012106

\section{Many years ago, in the early 60's, when I was about 11 years old, my classmate and I went to a far-away pharmacy after school. I no longer remember what took us there: perhaps we were planning to do chemical experiments, that required manganese and ammonia.}

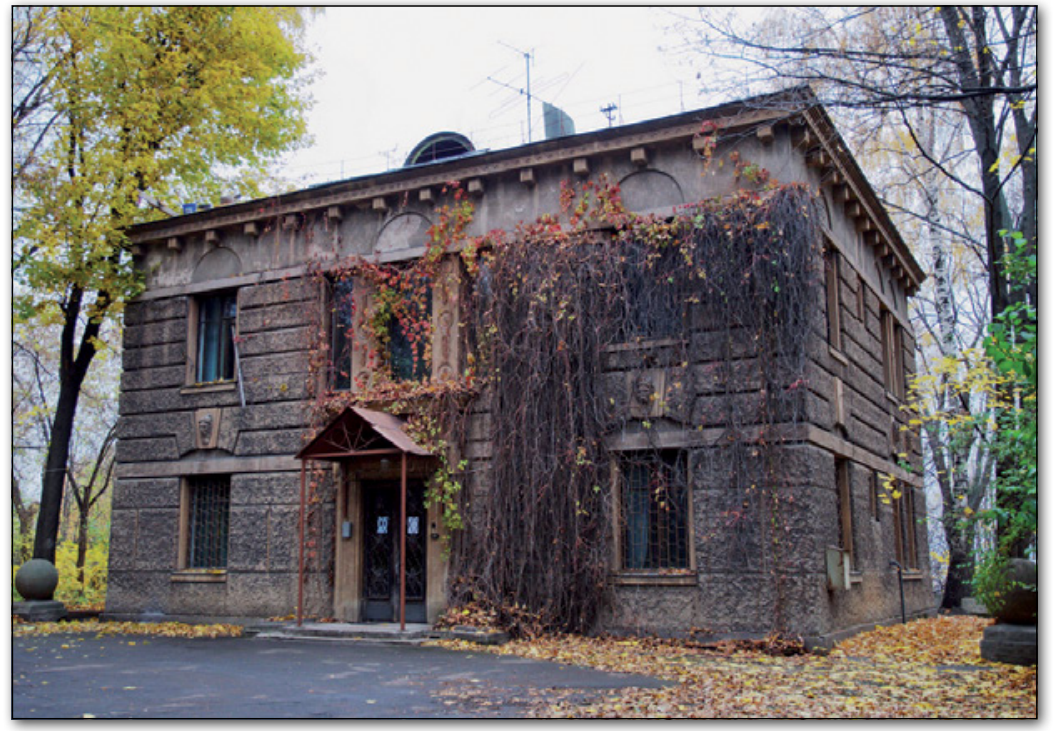

$\int$ t was a cold bright winter day. The walk was quite long. Over half way through, we were so cold that we no longer wished to buy anything. Then my friend suggested that we drop by her cousin's grandfather to get warm. We turned and walked through an iron gate, through a snow-covered park, past a frozen pond and walked into his house. After climbing wooden stairs to the second floor, we found ourselves in the study of Peter Kapitsa.

Low winter sun shone through the room, and dust particles played in its golden rays. The whole space seemed fabulously beautiful. The study distinctly smelled an aura of professor books, expensive leather furniture and a bit of tobacco. Piotr Leonidovitch no longer smoked then, but his pipe and a pack of good tobacco were always on his desk.

The change from the wintry streets was such that I stopped noticing details and sank into feelings, amazing ones. Taking upon himself the responsibility of an academy member, Kapitsa decided that the girls should get warm and poured a tiny glass of liqueur for each of us. Until then, I had never tasted alcohol. The sweet Benedictine was flowing into my relaxed body. It was one of the most memorable impressions of my childhood. Years later, destiny brought me into the same room, by then a museum. The same low winter sun shone through the room. Piles of marked up papers looked just the same. (Kapitsa had kept working on papers till his very last day.) Paintings, porcelain figurines on the chimney shelf, numerous crocodiles were all around - Crocodile was the nickname of Ernest Rutherford, Kapitsa's mentor and senior peer.

Today I am the director of the museum of Kapitsa. The more I learn about Kapitsa's life, the more I appreciate the scale of his personality.
4 Front of the Kapitsa Museum in Moscow

$\checkmark$ Piotr Kapitsa in 1929
In 1920 the young promising scientist lost his whole family - wife, two babies and father - to the influenza epidemic, so called "Spanish flu". It was the first major blow to his life - the first, but not the last. To help him keep living, his friends and colleagues sent him to Rutherford's laboratory at Cambridge. From 1923 Kapitsa worked at Cambridge, in Rutherford's laboratory. He met a Russian girl named Anna Krylova, who became his second wife and remained the person closest to him for the rest of his life. They built a home and had two sons. His experiments in cryogenics were so successful that in 1930 the Royal Society gave a special grant to the University of Cambridge for building a laboratory for research in low temperatures. On February 3, 1933, the laboratory was inaugurated with great pomp. His scientific prospects seemed unlimited. However, another blow was in the waiting. In the summer of 1934, when Kapitsa was visiting the Soviet Union to see his mother and take part in scientific conferences, he was not allowed to go back

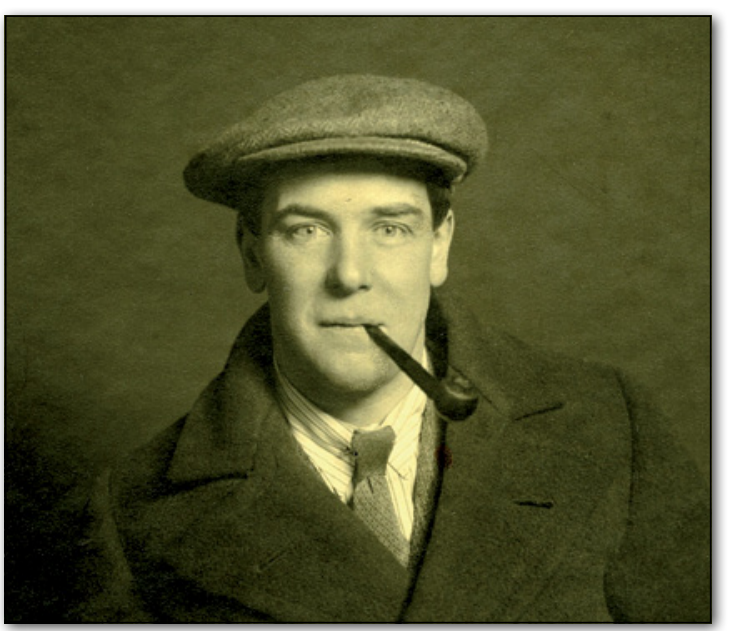




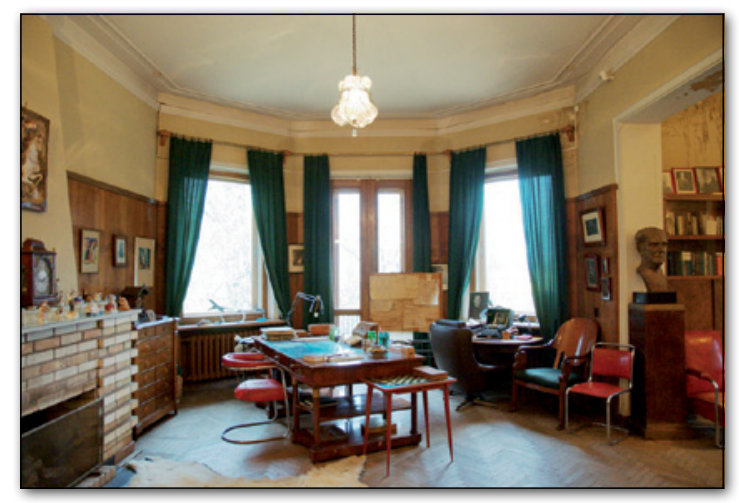

to England and was forced to establish a scientific laboratory in Moscow. After months of negotiations between the Soviet government on one hand and Rutherford and the Royal Society on the other, the cryogenic equipment of Kapitsa's laboratory was transferred from England to Moscow. This is how the Institute for Physical Problems was created. Kapitsa became its head and continued his research in cryogenics. His family moved from England to Moscow and they begin a new life in the Soviet Union. Soon, Kapitsa set up production of liquid oxygen. He saw and corresponded with highest officials of the country.

Kapitsa worked successfully until 1945, when the attention of the world, and especially that of physicists, turned to the problem of the atomic bomb. In the Soviet Union, the atomic project was supervised by the head of the KGB Lavrentiy Beria. Beria brought together the most prominent scientists and invited Kapitsa too. But Beria knew nothing about physics, and Kapitsa refused to work under him. The payback followed right away: Kapitsa was removed from all of his positions. Perhaps, he was lucky to have survived at all (it's important to say, that in the Soviet reality "invited" meant "forced to" while "to refuse" meant virtually "to commit suicide". So, the fact that Kapitsa and his family survived was a kind of miracle). For the third time, all he has achieved was destroyed. And, for the third time, Kapitsa managed to survive the blow, start from scratch and succeed again. Kapitsa spent eight years in disgrace. Most of the time he lived at his dacha outside Moscow. There, in a shack, he

set up a laboratory and kept working. After a while, his closest aide joined him, and his sons too were helping their father.

Upon the end of Stalin's era, Kapitsa returned to his institute. From then until his death in 1984, he lived in the mansion deep in the park, where I began my story. The Institute of Physical Problems was again an oasis in the minds of students. His home saw not only scientists of all stripes and colors, but artists, poets, musicians too were frequent guests in the mansion. How could one have a mansion in Moscow in the sixties? It was exceptional. It was Kapitsa's caliber that made it possible. After Piotr Leonidovich passed away, the Academy of Sciences decided to preserve his study as a memorial museum. Kapitsa's widow, Anna Alexeevna did a lot to help. She managed to create the effect of presence - it seems as if he has just stepped out and is about to be back. Yet, the exhibit shows the entire life of the scientist, both his moments of his international fame and his dark days of scary prospects, when some of his friends would cross the street to avoid him.

The museum contains the pieces of scientific equipment which Kapitsa was working with for many years. Part of it came here from Cambridge, another part was created with Kapitsa own hands. He was not only scientist, but a practical engineer, and was fond of designing things. Among the museum masterpieces there is a wooden table that never staggers.

v Kapitsa living-room in the museum

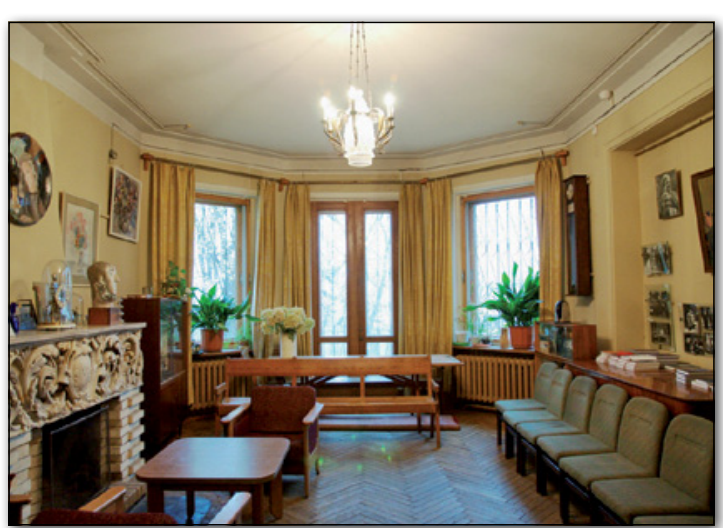

Moscow. Among them are unique delicately made glass pieces with which superfluidity of liquid helium was discovered and studied.

Outstanding experimentalist, Kapitsa was handy and loved making all that might be needed, whether devices or furniture. One of his hobbies was repairing antique clocks. Therefore, the exhibit takes shows a lathe and, by it, a little clock lathe. Also there, is a specially designed wooden table that does not wobble, no matter how uneven the floor, that he made at his dacha in 1948.

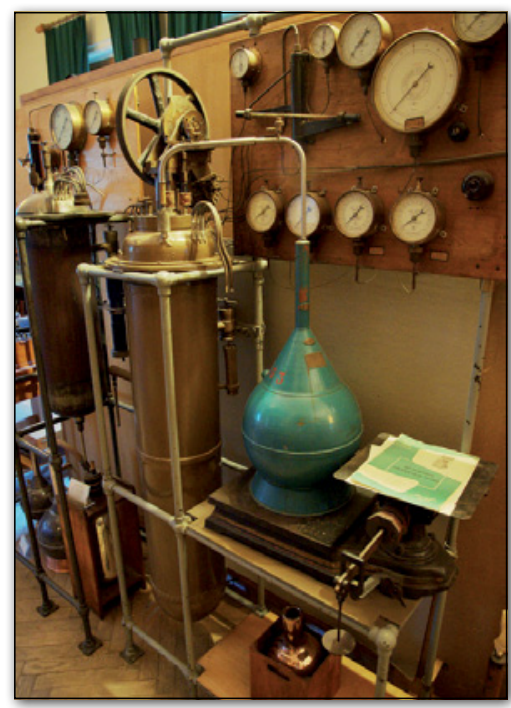

$\Delta$ The museum-kept nitrogen and oxygen liquefier of Kapitsa

Among the rest, the exhibit shows a unique collection of photos of prominent people, most of them autographed. Back in England, Kapitsa began to share photos with his fellow physicists. Above his desk was a whole portrait gallery of scientists. Photos of other famous people were added later. For example, in 1946 the leader of Yugoslavia, Marshal Tito arrived in Moscow. He visited Kapitsa's Institute and soon sent Kapitsa his autographed photo. When many years later, in 1966, Peter Leonidovich visited Yugoslavia, President Tito received him and awarded him the Order.

A lot of other medals and diplomas are displayed in the museum, reflecting an enormous global recognition of Kapitsa - a scholar and public figure, among them is the Nobel prize certificate, he obtained in 1978 . 